\title{
TEATRO, ÉTICA E RESISTÊNCIA
}

TEATRO, ÉTICA Y RESISTENCIA

Sara Rojo

ENTREVISTA POR:
Sara Rojo é professora Titular da UFMG e bolsista de produtividade do CNPq. Possui graduação em Letras pela PUC-Chile (1979) Mestrado em Artes pela State University of New York (1989) Mestrado em Letras Hispânicas pela PUC-Chile (1985) e doutorado em Literaturas Hispânicas pela State University of New York (1991). Realizou dois pós-doutorados, na Università degli Stud di Bologna (2001) e na Universidad de Chile (2007). Fundou em 1995, em Belo Horizonte, o Mayombe Grupo de Teatro e, desde então, assumiu a direção dos 12 espetáculos do grupo. Fo indicada ao Prêmio Sinparc de Melhor Direção, em 2013, pelo indicá a Kĺssico (com K). Em 2011, foi indicada aos premios Sated MG Ke Melhor Direça Teatrale Prêmi Sinparc de Melhor Sired̃a Tearal pelo espetaculo A Pequenina America. Desde Direção Teatral pelo espetáculo A Pequenina América. Desde 2014, é também diretora do Mulheres Míticas. Em 2018, o espetáculo "O Deszerto" foi eleito pelo $4^{\circ}$ Prêmio Beagá Cool como obra de arte que mais se destacou em Belo Horizonte em 2017. Possui livros, artigos e capítulos publicados em diversos países sobre teatro latino-americano, literatura e cinema. 2felipecordeiro@gmail.com

Doutorando em Letras - Estudos Literários pela FALE/UFMG, com bolsa CAPES. Possui o titulo de Mestre pela mesma instituição. É bacharel em Interpretação Teatral pela EBA/UFMG.

Sara Rojo es profesora Titular de la Universidade Federal de Minas Gerais y bolsista de productividad del CNPq. Posee graduación en Letras pela PUC-Chile (1979), Master of Arts por State University of New York (1989), Magister en Letras Hispánicas po PUC-Chile (1985) y doctorado en Literaturas Hispánicas por State University of New York (1991). Realizó dos pos-doctorados, en la Università degli Studi di Bologna (2001) e en Universidad de Chile (2007). Fundó en 1995, en Belo Horizonte, Mayombe Grupo de Teatro y, desde entonces, dirigió 12 espectáculos de ese grupo. Fue indicada al Premio Sinparc de Mejor Dirección Teatral, en 2013 por "Klássico (com K)". En 2011, fue indicada a Tos premios 2013, por "Klássico (comK)". En 2011, fue indicada a los premios Sated-MG de Mejor Dirección Tearr "A Premio Sinparc de Mejor Dirección Teatral por el espectáculo “A Pequenina América e sua avó \$ifrada de escrúpulos". Desde 2014, es también directora do Mulheres Míticas. En 2018, el espectáculo “El Deszerto" fue elegido por el $4^{\circ}$ Premio Beagá Cool como la obra de arte que más se destacó en Belo Horizonte en 2017. Posee libros, artículos capítulos publicados en diversos países sobre teatro latinoamericano, literatura y cine. 
EM 1998, VOCÊ FOI DESIGNADA PELA REITORIA DA UFMG, JUNTAMENTE COM OS PROFESSORES FERNANDO MENCARELLI E LEDA MARTINS, PARA COMPOR A COMISSÃO QUE VIRIA A IMPLEMENTAR, NO ANO SEGUINTE, O CURSO DE GRADUAÇÃO EM TEATRO DA UFMG - NAS MODALIDADES BACHARELADO E LICENCIATURA. PASSADOS 19 ANOS, COMO VOCÊ ENXERGA A EXISTÊNCIA DO CURSO EM DIÁLOGO COM A UNIVERSIDADE E TAMBÉM COM A CIDADE DE BELO HORIZONTE?

Também participou a professora Bya Braga. O curso se solidificou e ganhou especificidades com o trabalho de muitos colegas. Por exemplo, nasceu há alguns a nos o curso de Dança. Hoje a Escola de Belas Artes tem uma importante pesquisa, extensão e ensino nessa área, com uma Pós-Graduação que se destaca, no universo de seus pares, por ser uma das mais bem avaliadas da UFMG e do país. Isso é possível porque, entre outras coisas, existe um diá logo com a Universidade, a Capes, o CNPq e a Fapemig.

Por outro lado, o diálogo com a cidade nasce nas práticas dos formandos. Há muitos grupos que nasceram dos encontros, da pesquisa desenvolvida na UFMG, do estímulo das aulas. Por exemplo, Invertido, Quatroloscinco e Mulheres Míticas; outros artistas se incorporaram a grupos existentes como Marina Arthuzzi, Marina Viana, Éder Rodrigues e Fabrício Trinidade ao Mayombe Grupo de Tea tro. Falo destes grupos por estar ligada direta mente a eles; mas têm muitos outros.
As áreas de Humanas e Artes são fundamentais para a construção de uma Universidade brasileira capaz de produzir conhecimentos e sensibilidades que dialoguem com a sociedade. Celebro ter participado dessa Comissão que implementou o Curso.

EM 2014, A CRÍTICA DE TEATRO LUCIANA ROMAGNOLLI (HORIZONTE DA CENA E DOCUMENTACENA - PLATAFORMA DE CRÍTICA) DISSE QUE, DE ALGUMA MANEIRA, VOCÊ ERA INFLUENCIADORA DA MAIOR PARTE DOS GRUPOS DE TEATRO CONTEMPORÂNEOS DA CIDADE. COMO VOCÊ PERCEBE SEU CONTATO COM A CENA BELO-HORIZONTINA NESSAS DUAS ÚLTIMAS DÉCADAS? (COMO PROFESSORA, DIRETORA, TEÓRICA, TRADUTORA ETC).

Acredito que essa a firmação é excessiva. Mas o fa to de dar a ulas no Curso de Graduação em Tea tro e no Programa de Pós-Graduação em Letras - Estudos Literários da UFMG, me permitiu ter um conta to criativo com muitos grupos e um diálogo constante com os artistas da cidade. Talvez tenha ajudado no que escrevo. Sempre afirmo que para fazer crítica teatral (no meu caso, acadêmica), é preciso um conta to direto com o fazer teatral. Não podemos ter apenas uma aproximação teórica, assim como ta mbém acredito que não é suficiente para a crítica uma aproximação apenas empírica. 
APESAR DE O BRASIL SER UM PAIS COPIOSAMENTE MISÓGINO, TENHO A SENSAÇÃO DE QUE O TEATRO, MUITAS VEZES, COSTUMA IR NA CONTRAMÃO DESSES DISCURSOS QUE DES PREZAM AS MULHERES. EM BELO HORIZONTE, POR EXEMPLO, DIRETORAS COMO VOCÊ, IONE DE MEDEIROS, CIDA FALABELLA E RITA CLEMENTE, POSSUEM CARREIRAS MUITO SÓLIDAS E RESPEITADAS PELA CLASSE TEATRAL. ATUALMENTE, ENXERGAMOS TAMBÉM FORMAS MAIS PLURAIS SOBRE O QUE É SER MULHER, COM UMA REPRESENTATIVIDADE MAIS CONSTANTE DE TRAVESTIS E TRANSEXUAIS EM CENA. DESDE SUAS PRIMEIRAS PESOUISAS TEÓRICAS SOBRE A PRESENÇA DA MULHER NO TEATRO ATÉ A ATUALIDADE, VOCÊ ENXERGA AVANÇOS SIGNIFICATIVOS OU O CORPO DA MULHER É CONTINUAMENTE UM CAMPO DE BATALHA?

Obrigada por me colocar do lado de pessoas que admiro muito. Sim, as mulheres hoje têm um discurso no campo social e artístico infinitamente maior que em 1993 quando cheguei no Brasil. Costumo contar que no dia 8 de março de 1994 saí à rua para ir ao ato no qual, na minha cabeça, estariam as mulheres. Encontrei dois carros de centrais sindicais com homens falando para outros quatro ou cinco homens. Hoje isso mudou muito: temos passeatas, atos e dirigentes maravilhosas como a Cida Falabella e a Beatriz Cerqueira. No campo da arte, cresceu e se consolidou o existente. Ione tem mais de 40 anos fazendo um trabalho da melhor qualidade, não podemos pensar que tudo começou agora. Tudo demora muito, por isso são tão duros os retrocessos.

ANTES DE VIR AO BRASIL, VOCÊ FOI ALUNA DE AUGUSTO BOAL EM UMA RESIDÊNCIA ARTÍSTICA EM SANTIAGO E DIRIGIU GRUPOS DE CAMPONESES. CONTE-NOS UM POUCO SOBRE ESSE INÍCIO DE SUA CARREIRA ARTÍSTICA.

Os tempos sombrios atingem todas as áreas e as pessoas buscam formas de respirar. CENECA, uma organização não governamental (ONG) desenvolvia trabalhos na área de cultura. Entramos, dentro desse guarda-chuva, num projeto de criar grupos de teatro camponeses a partir das ideias de Augusto Boal e de quem encontrássemos para estar $\operatorname{com}^{1}$ (como se diz hoje) e não fazer para ${ }^{2}$. Foi muito intenso, aprendi muito. Assim, quando se divulgou entre os artistas uma residência de três dias, fui a primeira a querer participar.

O TEMA DESTE NOSSO DOSSIÊ É TEATRO \& ÉTICA. DENTRE OS ARTIGOS QUE RECEBEMOS, O NOME MAIS RECORRENTE FOI O DE GUILLERMO CALDERÓN. POR QUE O TRABALHO DELE ESTA TÃO INTIMAMENTE RELACIONADO COM UMA DIMENSÃO ÉTICA?

A dramaturgia de Guillermo Calderón, nos últimos anos, tem ocupado grande parte das horas de minha pesquisa por cinco caminhos: escrevendo e publicando sobre
1. Grifo e Nota do Editor: Aqui a entrevistada faz referência às pesquisas do Dr. Marcos Antônio (UFMG) quando, ao $s$ diz pran buscando trazer, na medida

pocándo trazer, na medida do o discurso - e não falar por eles.

2. Grifo do editor 
4. LAMPERT, $O$ desmonte da universidade pública: a interface de uma ideologia, online. suas peças (inclusive no meu último livro - Teatro LatinoAmericano em Diálogo. Produção e Visibilidade [2008], Editora Javali); ensinando seus textos em sala de aula (na graduação e na pós-graduação, não só do Brasil); orientando pessoas que querem desenvolver trabalhos a partir de seus escritos (entre elas, Luísa Lagoeiro), traduzindo do espanhol ao português (com um parceiro excepcional, Assis Benevenuto) e, ultimamente, dirigindo uma peça dele, Classe (Grupo Mulheres Míticas).

Essa energia relaciona-se com o fato de que é um autor que provocou em mim muitos questionamentos éticos sobre temas atuais. Nos seus textos, nada do que é colocado é simples e fácil de ter uma resposta. Tudo é questionado e questionável. A tomada de posição que ele faz leva o espectador/leitor a pensar em nossos próprios posiciona mentos, nas versões do passado como construtoras de nosso presente e nos temas polêmicos, por exemplo o mito de Pablo Neruda no filme Neruda ${ }^{3}$ (roteiro de Guillermo Calderón). A ética tem a ver, neste caso, com exigir do espectador/ leitor uma tomada de posição própria, não entregada priori no corpo da obra. Esse exercício em tempos em que o sujeito está disposto a absorver o que lhe entregam sem questionamento, sem revisar a veracidade do conteúdo, é muito importante.
DIANTE DOS CONSTANTES DESMONTES QUE AS ARTES E O ENSINO PÚBLICO ESTÃO SOFRENDO NO PAÍS, QUAIS DESAFIOS VOCÊ IMAGINA QUE OS ARTISTAS DE TEATRO ENFRENTARÃO NOS PRÓXIMOS ANOS?

Como lhe falei os tempos sombrios atingem todas as áreas. Por ser esta uma revista universitária e de arte, falarei apenas dessas duas. $\mathrm{O}$ ensino universitário foi tardio no Brasil. A primeira universidade da América Latina é de 1532, na República Dominicana. Em 1918 estava sendo realizada a primeira reforma para a democratização da universidade em Córdoba (Argentina). No Brasil só no início do século XX

A Constituição de 1934 abriu caminhos para a criação da Universidade de São Paulo e, através da Lei n 452/1937, criou-se a Universidade do Brasil, como reorganização da Universidade do Rio de Janeiro, de 1920, que foi fruto da junção das escolas tradicionais de Direito, Engenharia e Medicina, existentes no Rio de Janeiro. Tal processo ocorreu para que pudesse ser outorgado o título de doctor honoris causa ao rei da Bélgica, que visitava o país por ocasião do Centenário da Independência. ${ }^{4}$

Desta forma, podemos observar que o caminho desde sua origem foi difícil e que os avanços das últimas décadas nas universidades públicas foram muitos (pesquisa,
3. N.E.: Filme franco-argentinochileno-hispano-estadunidens de 2016, do gênero drama biográfico, dirigido por Pablo Larraín é escrito por Guillermo Calderón. Foi selecionado como de Melhor Filmo Estrangero 
extensão, ensino, inclusão) e, mesmo assim, falta muito por fazer. Só que o congelamento de gastos (na verdade, investimentos) por 20 anos produz um retrocesso e um estancamento nessa evolução. Nós, os professores e os estudantes, temos que manter o ensino, a pesquisa e a extensão de qualidade, conjunta mente com uma produção acadêmica de reconhecimento nacional e/ou internacional apesar das condições adversas. Essa é uma forma de defender a universidade pública.

A arte também está sofrendo um processo similar O Ministério de Cultura, depois do impeachment da Presidenta Dilma Rousseff, foi abolido e, tudo indica que o novo Presidente do Brasil, a partir de 2019, novamente o extinguirá. As leis de apoio à Cultura já estavam sendo reduzidas nos últimos dois anos, e, nas a tuais circunstâncias, não podemos esperar muito. Percebo que as alternativas são defender o papel da Arte para o pleno desenvolvimento do país e gerar novas formas de realização que nos permitam seguir fazendo arte. Nessa linha é interessante observar que o $60^{\circ}$ Prêmio Jabuti (2018) foi para a obra de poesia "à cidade" (Autor Independente), de Mailson Furtado Viana, e que a evolução do Tea tro Negro na cidade de Belo Horizonte surgiu do esforço pessoal de alguns artistas. A produção independente não é a situação ideal, mas é a alternativa que temos.

\section{REFERÊNCIAS}

AMPERT, Ernani. O desmonte da universidade pública: a interface de uma ideologia. Revista Linhas http://revistas. udesc.br/index.php/linhas/article/view/1342/1151, 2006. Acesso 10/11/2018. 